\title{
"Buen gobierno" y militarización de la administración en el Río de la Plata. La trayectoria del virrey Marqués Gabriel de Avilés y del Fierro*
}

\author{
"Good governance" and Militarization of the Administration in the Rio de la \\ Plata. The Trajectory of the Viceroy Marquis Gabriel de Avilés y del Fierro
}

EMANUEL CONTRERAS

\section{Resumen}

En el presente artículo se reconstruye y caracteriza, a partir de fuentes editas e inéditas, la trayectoria político militar de Gabriel Avilés y del Fierro hasta su nombramiento como virrey del Río de la Plata (17991801). En base a ello, nos proponemos analizar cómo distintos elementos constituyentes del ideal de "buen gobierno" atravesaron y justificaron su carrera dentro de la Monarquía Hispánica, inserta en un clima reformista, de guerras entre monarquías y militarización de sus cuerpos políticos.

\section{Palabras clave}

"Buen gobierno"; Gabriel Avilés; Monarquía Hispánica; Carrera Administrativa; Militarización.

\begin{abstract}
This article reconstructs and characterizes, from published and unpublished sources, the politicalmilitary career of Gabriel Avilés y del Fierro until his appointment as viceroy of the Río de la Plata (17991801). Based on this, we propose to analyze how different constituent elements of the ideal of "good government" crossed and justified his career within the Hispanic monarchy, inserted in a reformist climate of wars between monarchies and militarization of their political bodies.
\end{abstract}

Keywords

"Good governance"; Gabriel Aviles; Spanish Monarchy; Administrative Career; Militarization.

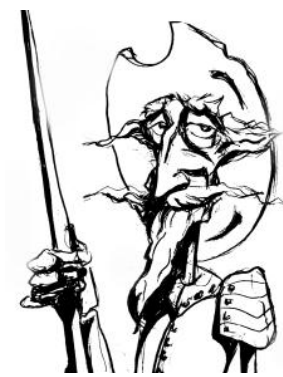

Recibido con pedido de publicación el 10 de febrero de 2021

Aceptado para su publicación el 2 de mayo de 2021

Versión definitiva recibida el 20 de junio de 2021

https://doi.org/10.35305/prohistoria.vi36.1516

Emanuel Contreras, Centro de Estudios Históricos, Universidad Nacional de Mar del Plata, Mar del Plata, Argentina; email: emanuel.contrerasmdq@gmail.com

* Agradezco los comentarios y las sugerencias de los evaluadores anónimos.

Esta obra se publica bajo licencia Creative Commons. Atribución-NoComercial-CompartirIgual 4.0 Internacional

Contreras, E. "Buen gobierno" y militarización de la administración en el Río de la Plata. La trayectoria del virrey Marqués Gabriel de Avilés y del Fierro. Prohistoria, Año XXIV, 36, dic. 2021, 1-27. 
La repentina muerte del virrey Pedro Melo de Portugal y Villena el 15 de abril de 1797, dejó al virreinato del Río de la Plata bajo las órdenes del Subinspector General de Ejército, Antonio Olaguer Feliú, en calidad de interino. Sin embargo, Carlos IV modificó esta situación mediante su real decreto, firmado en San Lorenzo el 19 de noviembre de 1797, por el cual designó como virrey al Teniente General, Gabriel Miguel Avilés y del Fierro IV Marques de Avilés. ${ }^{1}$ El 14 de marzo de 1799, con 64 años y una nutrida carrera dentro de la monarquía, Avilés ingresó a la ciudad de Buenos Aires y tomó su cargo como séptimo virrey del Río de la Plata. ${ }^{2}$

En este artículo nos proponemos, a partir de fuentes editas e inéditas, reconstruir y analizar la trayectoria política-militar de Gabriel de Avilés dentro de la Monarquía Hispánica, hasta su nombramiento como virrey rioplatense. Pretendemos identificar y caracterizar cómo diferentes concepciones vinculadas al ideal de "buen gobierno" jalonaron la trayectoria del marqués hasta su nombramiento como virrey, imbuida en un contexto de guerras y reformas dentro de la propia monarquía. Prestaremos atención a los elementos que fueron ponderados a lo largo de su carrera, es decir los logros, servicios, méritos, vínculos y venalidades que le valieron sus ascensos.

Pensar dentro del contexto de finales del siglo XVIII en la Monarquía Hispánica implica imbuirnos de un tópico que la historiografía ha debatido y continúa reinterpretando: las denominadas "reformas borbónicas". Lejos de intentar realizar un estado de la cuestión que agote todas las vertientes que la historiografía sobre las reformas ha suscitado (con acento en diferentes aspectos: económicos, políticos, etc.) pueden señalarse sucintamente algunos aspectos centrales de cómo evolucionó la agenda historiográfica de las últimas décadas en torno al examen del reformismo durante el siglo XVIII.

Los trabajos más sobresalientes en referencia al reformismo borbónico y su aplicación en América han articulado su mirada a partir de la noción de Estado colonial y de las diferentes formas -y causas- que adoptó un proceso de concentración y centralización del poder real protagonizado por la dinastía borbónica durante el siglo XVIII, con particular énfasis en su segunda mitad. ${ }^{3}$

\footnotetext{
${ }^{1}$ Archivo General de la Provincia de Santa Fe, Cabildo de Santa Fe, Actas capitulares, Tomo: XVI folios $504 \quad$ a $\quad 505$ v. [en línea] https://actascabildo.santafe.gob.ar/actascabildo/default/ficha/5984-27 de Febrero de 1799.

2 Archivo General de Indias, ESTADO, 80, N.67, Virrey de Buenos Aires sobre toma de posesión del mando, [en línea] http://pares.mcu.es/ParesBusquedas20/catalogo/show/67273?nm.

3 Entre muchas obras, cabe destacar el trabajo de John Lynch (1973) que presentaba al reformismo borbón motivado por la necesidad de una mayor eficacia en el gobierno y control sobre las colonias americanas. Horst Pietschmann (1972; 1990) destacaba en cambio el componente religioso del reformismo borbón y su adhesión a la monarquía absoluta, en tanto David Brading (1984) suponía a las "reformas" como un paquete de medidas destinado a reforzar el intervencionismo y revertir el debilitamiento interno del imperio español. Halperín
} 
En cambio, durante las últimas décadas esta perspectiva ha dejado lugar a investigaciones que ponderan la existencia de una monarquía española de carácter jurisdiccional que, ${ }^{4}$ bajo las directrices borbónicas, intentó volverse más ejecutiva en sus territorios americanos, ${ }^{5}$ consolidando y ampliando las esferas de intervención y decisión propias de la Corona por sobre los restantes cuerpos de la monarquía.

Algunos de estos nuevos estudios proponen poner en tensión esta idea tradicional que ha atribuido un sentido unidireccional y vertical a las "reformas" (Ciaramitaro, 2008, Sánchez Santiró, 2016) así como también cuestionar su concepción como un paquete de medidas prefijadas e impuestas por la Corona, que debieron enfrentarse a dificultades operativas y resistencias. De esta forma, discuten tanto la idea de centralización, como las visiones estatalistas, cuestionan las periodizaciones tradicionales, entendiendo el proceso durante todo el siglo XVIII americano -ya no solo centrado en el gobierno de Carlos IIIy revalorizando el papel de los sectores locales e intermedios dentro del contexto reformista (Sánchez de Tagle, 2010; Morelli, 2008 y 2015). ${ }^{6}$

El contexto histórico en el cual se inscribe nuestro estudio sobre la trayectoria de Avilés nos ubica dentro de un clima de expansión y aumento de la intensidad de los conflictos europeos en todos los territorios hispánicos, siendo la instauración del Virreinato del Río de la Plata en 1776 una de sus consecuencias inmediatas. La frontera americana austral de la monarquía constituía un espacio de contactos múltiples y heterogéneos. Hacia su interior podían encontrarse los pueblos originarios no sometidos al control hispánico y hacia los "márgenes", tanto la amenaza portuguesa como las ambiciones atlánticas de otras potencias europeas. El virreinato rioplatense se constituyó

Donghi (1961) puso el acento, en cambio, en el intento de transformación del vínculo metrópolicolonias que, a partir de convertir a las segundas en mercado para la primera, permitirían el resurgimiento militar de España en un contexto europeo cada vez más volátil y contrario al Imperio Borbón. La consolidación del concepto de "reformas borbónicas" y su vinculación a la idea de aumento del poder del monarca en detrimento de la autonomía de los grupos de poder indiano puede apreciarse ya en Pérez Herrero (1991).

${ }^{4}$ Sobre el carácter jurisdiccional de las monarquías de antiguo régimen, ver Hespanha (1984).

${ }^{5}$ La mayor ejecutividad buscaba la desaparición de la tradicional configuración agregativa de la Monarquía Hispánica, y su sustitución por una formación cimentada según el modelo de gobierno de uno de sus cuerpos, esto es, la corona de Castilla. Este proceso implicaría la asimilación de todos los territorios al modelo castellano, la restructuración del equilibrio de poder con las distintas corporaciones y una reorganización de la administración territorial que superara el ámbito local, para así evitar los tradicionales cuerpos intermedios y polisinodiales (Fernández Albadalejo, 1984). La búsqueda de esta mayor capacidad ejecutiva pretendía la reafirmación del poder regio sin destruir la tradición pactista y negociada propia de la Monarquía Hispánica (Cardim, 2005).

${ }^{6}$ Sobre las nuevas perspectivas acerca de los niveles y formas de integración de los múltiples territorios de la monarquía española, así como sobre la relación entre corona y sus posesiones, puede consultarse: Rivero Rodríguez (2013); Ruiz Ibáñez (2016); Amadori (2016). 
como la barrera de contención frente a estos grupos, así como en la vía de control y resguardo del puerto de Buenos Aires, ingreso al corazón de las riquezas argentíferas de Potosí.

Ya fuera por la necesidad de recursos, la búsqueda de apoyos políticos, el avance de los enemigos sobre la América hispánica, la reconfiguración territorial o la necesidad de viabilizar diferentes cambios o reformas, la monarquía debió contar con nuevos hombres y nuevas instituciones para estos fines. Sería la oficialidad militar quien, a lo largo de todo el siglo XVIII, avanzaría en ocupar no solo puestos referentes a su profesión sino también aquellos con carácter relativo a la administración y al gobierno (Marchena; 1983: 7). Sin embargo, la historiografía ha señalado cómo esta lógica no respondería a un aumento de la relevancia del ejército, sino más bien a una valorización creciente de "la vía militar", es decir la vía ejecutiva, para nombramientos y acciones concretas de gobierno (Dedieu; 2007: 13).

En el caso del Río de la Plata, trabajos como los de Tarrago (2012) y Forconi (2019) sobre la gobernación de Buenos Aires y la tenencia de gobernación santefecina, respectivamente, demuestran cómo el recurso a funcionarios de carrera militar constituyó una forma de equipamiento político del territorio rioplatense en un contexto signado por las disputas territorialesfronterizas, este procesos de militarización como sostienen Birocco (2015) y Trujillo (2017) se encuentra presente en el territorio rioplatense con anterioridad a la llegada de los Borbones. Por su parte, otras investigaciones interpretan la tendencia hacia la militarización de la administración rioplatense como resultado de un proceso de centralización del poder fuertemente vinculado al absolutismo (Abásolo, 2005). ${ }^{7}$

Considerando que la lógica militar formaba parte de un universo mayor de aptitudes que los agentes de la monarquía debían cumplimentar. Centraremos nuestro enfoque de análisis a partir de agentes concretos sobre quienes recayó el ejercicio del gobierno de la monarquía, buscando rescatar las nociones atribuidas al "buen gobierno" 8 que fueron ponderadas

\footnotetext{
${ }^{7}$ Sostiene Abásolo "la militarización de la monarquía borbónica no significó conformar un reino dedicado al ejercicio primordial de la guerra. Se trató en cambio de adoptar dispositivos tendientes a articular la sociedad bajo parámetros orgánicos férreamente verticalizados" (2005: 64-65).

${ }^{8}$ La buena administración de justicia para estas sociedades constituía la esencia del "buen gobierno". Esta justicia consistía en "dar a cada uno lo que le pertenece", respetando las potestades y privilegios, de las personas y de los grupos; recompensando los méritos y sancionando las faltas. De ella dependía la unión del cuerpo político: las relaciones armoniosas entre sus miembros y la consecución de sus fines. La ausencia de justicia, de buena justicia, ponía en peligro el orden social y hacía imposible la consecución del "bien común" (Guerra, 2003: 2012). Por ello, "buen gobierno" entendido como el ideal atribuido al "gobierno de la casa" en tanto modelo administrativo, comprendía la distribución de premios y castigos dentro
} 
El ejercicio de los oficios de gobierno dentro de las monarquías de antiguo régimen poseía un carácter personal. Los puestos de la administración se encontraban fuertemente permeados por las características, el accionar, así como los vínculos y ambiciones que tuvieran las personas que los ejercían. ${ }^{9}$ En este sentido, Malagón Pinzón (2005) señala que, durante el desarrollo del siglo XVIII, sobre todo en la segunda mitad, se intentaron afianzar algunos criterios ya existentes y establecer nuevos preceptos tanto para el ingreso como para el ejercicio de cargos en la administración, que constituyeron formas de intervención sobre el aparato "burocrático".

Consideramos entonces que el examen del caso del marqués de Avilés, inserto dentro del proceso de militarización de los cuerpos políticos, nos permitirá apreciar de qué modo elementos y concepciones vinculados al ideal de "buen gobierno" operaron en la trayectoria de los agentes reales. ${ }^{10}$

\section{Gabriel de Avilés y del Fierro, IV Marques de Avilés}

\section{Los Avilés, una familia "al servicio de Rey"}

Gabriel Miguel Avilés y del Fierro nació en el año 1735 en la ciudad catalana de Vich al momento en que su padre José de Avilés e Iturbide, originario de Sevilla, se hallaba ejerciendo el cargo de corregidor en dicha ciudad. ${ }^{11}$

José de Avilés, originario de la villa homónima, ingresó a los ejércitos de S. M. en el año 1700 como soldado, participando en la Guerra de Sucesión Española (1701-1715) a favor de la causa borbónica. La acumulación de méritos

de una "geometría variable" de uso discrecional y no por ello arbitraria, ligada a la preservación de los equilibrios (Garriga, 2006: 152-153).

${ }_{9}$ Por lo tanto, la valoración del gobierno se correspondía directamente con la valoración de agentes concretos, tanto en el desempeño de sus oficios, como en sus negocios particulares. Dentro de la esfera doméstica de los agentes se conceptuaban aspectos como el gobierno de sus casas, su grado de devoción cristiana, sus buenas costumbres, el respeto por las distintas jurisdicciones o el servicio que hubieran prestado hacia ambas majestades (Lempérière, 2008: 12).

${ }^{10}$ Nuestro trabajo no buscará ser una reconstrucción teórica sobre la definición del concepto de buen gobierno a través de tratadistas o eruditos de la época, sino que solo se limitará a advertir sobre cómo fue utilizado en la práctica dentro de la administración, entendida esta como parte de una construcción política.

${ }^{11}$ Como consecuencia del pacto de Génova de 1705, firmado a favor de la causa del Archiduque Carlos y la feroz resistencia a capitular ante las tropas de Felipe V, hecho que se produjo finalmente el 12 de septiembre de 1714, Cataluña quedo en una posición muy desfavorable frente a la nueva dinástica gobernante. En consecuencia, el Principado de Cataluña se vio perjudicado en sus fueros por los "Derecho de Nueva Planta", promulgados el 16 de enero de 1716 , con los cuales se disolvieron varias instituciones locales y se implantaron otras castellanas. Entre las medidas más importantes el cargo de virrey fue suprimido y reemplazado por el de capitán general y la jurisdicción se dividió en doce corregidurías. Para más información ver: Dedieu (2000). 
y servicios le valieron para el año 1743 obtener, luego de una nutrida carrera, el grado de Brigadier de Dragones. No obstante, los servicios de Don José no se circunscribieron al plano militar, sino que ocupó varias plazas en la administración del reino, siendo gobernador militar, corregidor e intendente. El 2 de abril de 1761, luego de toda una vida al servicio de la Corona, le fue concedido por gracia de S.M. Carlos III el título de I Marqués de Avilés (De Cadenas y López, 1991: 14). Durante muchos años se consideró que algunos empleos dentro de la administración requerían grado de nobleza en los agentes que pudieran cubrirlos, "asegurando" así ciertas características en los poseedores de los cargos que resultarían útiles para la monarquía. Cada vez más casos y eruditos a lo largo del siglo XVIII, sobre todo luego de la segunda mitad, sostenían que no debía tenerse en cuenta el nacimiento o grandeza sino la sabiduría, morigeración, actividad, prudencia y desinterés de los candidatos a ocupar cargos. En consonancia a partir de este periodo muchos de los cargos fueron ocupados por personas que siguieron "la carrera de la administración", iniciando desde los escalafones más bajos y careciendo de títulos nobiliarios u ostentando títulos de reciente creación. Hacia finales del siglo XVIII la preocupación por la cuna del agente quedó reducida a la exigencia de un cierto decoro familiar que solía calificarse como "decencia” (Urquijo, 1998: 132).

La familia Avilés formó parte de los grupos favorecidos por la Guerra de Sucesión y las reformas políticas y administrativas emprendidas por los Borbones. ${ }^{12}$ Miembros de estos grupos ascendieron en gran número a posiciones privilegiadas en la Corte y a cargos encumbrados en las finanzas reales, en la alta administración, en el ejército, la marina y la iglesia, así como a posiciones destacadas en el comercio colonial y en el gobierno de las indias. Establecidos dentro de la administración de la monarquía, los miembros de estos grupos familiares se reprodujeron y sus posiciones influyentes les permitieron colocar a sus jóvenes parientes en elevadas carreras militares, que tradicionalmente habían sido restringidas a la alta nobleza (Imizcoz, 2011; 15). Una de las claves principales del éxito de estas políticas familiares fue la identificación de sus propios intereses, sus propias empresas y manejos con los intereses de la Corona (Tarragó, 2017: 98). Debemos tener presente que la estimación de estos hombres no solo dependía de sí mismos: sus filiaciones

\footnotetext{
${ }_{12}$ Pese a verse notablemente afectada durante la etapa borbónica por la pérdida del monopolio comercial americano y el traslado de sus instituciones a la ciudad puerto de Cádiz, Sevilla fue una de las plazas que apoyo los derechos de Felipe de Anjou, desde el comienzo de la disputa dinástica. A su vez entre 1729 y 1733 la corte real de Felipe V se trasladó a la ciudad, en el periodo conocido como "lustro real". En este sentido algunos sectores sociales se vieron notablemente favorecidos con el triunfo borbónico, llegando a ocupar diferentes plazas en la administración real gracias a la identificación de sus propios intereses, sus propias empresas y manejos con los intereses de la Corona. Para más información ver: Andújar Castillo (2006).
} 
influían sobre su propia valoración a través del accionar de sus familiares, allegados y criados. Para la Monarquía el agente y sus allegados debían observar una conducta que sirviera de ejemplo a los súbditos del lugar (Pereyra, 2017: 29).

Una de las prácticas más comunes dentro de este proceso de reconfiguración y reposicionamiento de las elites, fue la adquisición de grados de oficialidad militar costeando la formación de compañías, un tipo de venalidad indirecta muy utilizado durante los reinados de los primeros borbones. De manera que frente a la necesidad de formar nuevos cuerpos de ejército la monarquía fomentó la creación de estas “compañías de aumento", a través de asentistas que poseían despachos de oficiales de las unidades firmados en blanco por el Rey. A cambio de acceder a oficialidades estos "empresarios de la guerra" debían entregar regimientos completos de hombres vestidos y armados. Quienes accedían a los cargos de mando no debían acreditar servicio alguno y se suponía que el aprendizaje llegaría con la experiencia en la jefatura de las unidades (Benavent, 2002: 272). Esta práctica permitió a los compradores alcanzar ascenso social, estabilidad económica y la adquisición de nobleza, sobre todo entre grupos sociales emergentes y acaudalados. ${ }^{13}$

Resulta relevante entonces señalar que José Avilés, en una carta que dirigió al marqués de Esquilache, le manifestó que la formación militar de sus cuatro hijos varones le había ocasionado elevados gastos, al costear la formación de una "compañía de aumento" en el Regimiento de Dragones de la Reina (Andujar Castillo, 2004: 224). De esta manera los gemelos José y Miguel Avilés y del Fierro, gracias a las gestiones de su padre, alcanzaron en 1749 los grados de capitanes de dragones, agregándose ambos al regimiento de Lusitania. Por otra parte, para sus hijos menores Gabriel y Ramon Avilés y del Fierro la oportunidad llegó en el año 1762, cuando Don José adquirió para ellos una compañía y una tenencia. ${ }^{14}$

De esta manera, favorecida por la coyuntura de la Guerra de Sucesión y la capacidad de acceder a distintos grados militares a través de venalidades indirectas, la familia Avilés logró colocar a cada uno de sus cuatro hijos varones dentro de la carrera de las armas.

Gabriel Miguel Avilés por su parte ingresó con diecisiete años a los ejércitos de S.M. en 1752 con el grado de cadete y sería promovido en 1756 al de alférez, participando en la Guerra de los siete años específicamente en el sitio

\footnotetext{
${ }^{13}$ Para más información sobre esta práctica ver: Andújar Castillo (2004).

${ }^{14}$ Para los casos de José y Miguel de Avilés, AGS (Archivo General de Simancas), GM (Guerra y Marina) Leg. 2480, C. VIII; para los casos de Gabriel y Ramon Avilés y del Fierro, AGS, GM, Leg. 1144.
} 
a la ciudad de Almeida (1762), en el reino de Portugal. ${ }^{15}$ Después de haber obtenido el nombramiento como capitán del Regimiento de Dragones de la Reina, gracias a las gestiones de su padre en 1762, en el año 1768 Avilés pasó a América junto con los refuerzos de tropa comandadas por el capitán Baltazar Setmanat.

\section{América tierra de oportunidades}

La toma de las islas Malvinas por el comodoro británico John Byron en 1765, a las cuales dio por nombre Falkland, junto con la creación de un establecimiento permanente en las islas, representaban una amenaza directa a las posesiones americanas de la Monarquía Hispánica. En razón de ello, Carlos III resolvió ordenar al gobernador del Río de la Plata Francisco de Paula Bucarelli desalojar a las fuerzas británicas de las islas y ordenó enviar una expedición hacia las costas occidentales de América del sur, ante la posibilidad de un ataque inglés (Romero, 1901: 7). Las preocupaciones de la Monarquía, sin embargo, no solo se reducían al margen oriental del extremo sur de la América Hispánica, la costa del pacífico para aquel entonces representaba un espacio sumamente vulnerable de cara a las amenazas externas.

Respondiendo a este contexto, el capitán Avilés a sus treinta y tres años, desembarcó en Montevideo y viajó desde allí junto a treinta veteranos de caballería que debían servir de base para la instrucción de las milicias de esa arma en Chile, como parte de la política de fortalecimiento militar (Romero, 1901: 7). Durante su estancia en la región trasandina Avilés se colocó bajo las órdenes de Juan de Balmazeda y Zensano Beltrán permaneciendo en el Reino de Chile como ayudante de campo, por encargo de Balmazeda, ante la falta de oficialidad en la frontera sur. ${ }^{16}$

La región trasandina se encontraba sumida en enfrentamientos permanentes con las parcialidades mapuches, pehuenches y huilliches que ocasionaron importantes pérdidas para ambos bandos. Luego de varios años de conflicto la situación llego a un punto muerto y la Corona, que se encontraba afectada en su Real Hacienda como también en la disponibilidad de hombres de armas y milicianos, optó por negociar la paz. Así, la denominada "campaña

\footnotetext{
${ }^{15}$ Lanuza, Alberto Martín Apellido, "Gabriel de Avilés y del Fierro", en Real Academia de la Historia, Diccionario Biográfico electrónico. [en línea] http://dbe.rah.es/biografias/7117/gabriel-deaviles-y-del-fierro.

16 Juan de Balmazeda Zensano y Beltrán: Galilea (La Rioja), 16/4/1702 - Santiago de Chile (Chile), 30/5/1778. Oidor de la Real Audiencia de Santiago de Chile (1739 - 1773) y gobernador interino de la Capitanía General de Chile (entre el 24 de enero de 1768 y el 3 de marzo de 1770). Ver Barrientos, Grandon Javier, "Juan de Balmazeda Zensano y Beltrán" en Real Academia de la Historia, Diccionario Biográfico electrónico. [en línea] http://dbe.rah.es/biografias/47660/juande-balmazeda-zensano-y-beltran.
} 
sur" finalizó en el año 1771 con el parlamento de Negrete (Zavala Cepeda, 2015).

El derrotero de Avilés continuó hacia el virreinato del Perú, debido a la designación de Francisco Javier de Morales y Castejón de Arroyo como gobernador interino de Chile, ${ }^{17}$ por el virrey del Perú Manuel Amat y Juniet, ${ }^{18}$ para dirigir la guerra contra los araucanos en 1770. A raíz de ello, Avilés fue designado en el cargo interino de Sub-Inspector de milicias. El 27 de julio de 1770 asumió la dirección de las Milicias de Caballería y Dragones del reino del Perú, teniendo además el cargo de Instructor de todos los cuerpos de milicias españolas de caballería y dragones. ${ }^{19}$ Durante el ejercicio de los empleos de SubInspector se le dio el encargo de pasar revista, ordenar y formar a los siete regimientos ubicados en las provincias de Cañete y Pisco, ubicadas al sur de Lima, ante las sospechas de guerra y puntualmente frente a la amenaza de invasión desde la costa por los enemigos del reino. ${ }^{20}$

Dentro de la Monarquía Hispánica la acumulación de cargos no solo respondía a su propia lógica de gobierno, sino que además obedecía fundamentalmente, en tierras americanas, a la escasez de hombres para dichos puestos. Fue por esta razón, y ante los casos de ausencia, traslado o muerte de distintos oficiales, que el recorrido de Avilés dentro de la administración lo llevó a ocupar distintos cargos, como veremos a continuación.

El 5 de noviembre de 1771 ante la necesidad de un "oficial de honor y graduación” y de conducta de "bastante proporción”, Avilés tomó posesión del Gobierno de la Plaza y presidio del Callao, producto de la vacancia dejada por Pablo Bustamante, ejerciendo el cargo en condición de interino por el tiempo de diecinueve meses. ${ }^{21}$ Inmediatamente después de cesar en su cargo en el Callao, fue nombrado director del Monte Pio de Viudas y Pupilos de Militares desde el 23 de enero de 1772 hasta su reemplazo por el nuevo Inspector Gral. de Tropas

\footnotetext{
${ }_{17}$ Francisco Javier de Morales y Castejón de Arroyo: 1696 - 1774, gobernador interino de la Capitanía General de Chile (1770-1772). Ver: Medina, José Toribio (1906) Diccionario biográfico colonial de Chile. Imprenta Elezeviriana, Santiago de Chile, p. 553.

${ }_{18}$ Manuel Amat y Juniet: Vacarisas (Barcelona), 1704 - Barcelona, 1782. Militar, gobernador de la Capitanía General de Chile (1754-1761) virrey del Perú (1761-1776). Ver: Puente Brunke, Jose. "Manuel Amat y Juniet" en Real Academia de la Historia, Diccionario Biográfico electrónico, [en línea] http://dbe.rah.es/biografias/7149/manuel-de-amat-y-junyent.

19 AGI (en adelante AGI), LIMA, 653, N. 186. Carta N. 1165 de Manuel de Amat y Junyent, Virrey de Perú, a Julián de Arriaga, secretario de Marina e Indias, [en línea] http://pares.mcu.es/ParesBusquedas20/catalogo/description/3545116?nm.

${ }^{20}$ AGI, LIMA, 658, N. 5 Carta N 304 de Manuel de Guirior, Virrey de Perú, a José de Gálvez, secretario de Indias, [en línea] http:/pares.mcu.es/ParesBusquedas20/catalogo/description 3612371 ?nm .

${ }^{21}$ AGI, LIMA, 652, N. 145 Carta N 477 de Manuel de Amat y Junyent, virrey de Perú, a Julián de Arriaga, secretario de Indias, [en línea] http://pares.mcu.es/ParesBusquedas20/catalogo/description/359183?nm.
} 
Javier de Morales el 16 de julio de $1773 .{ }^{22}$ El 23 de enero del mismo año fue promovido a comandante propietario del Batallón fijo de la plaza del Callao, además de encargársele la instrucción de la caballería y dragones del virreinato, empleo con el cual fue comisionado, originalmente, a las tierras americanas por la Corona en 1768.

El recorrido sinuoso a través de diferentes cargos permitió a Avilés solicitar su promoción en el año de 1775, adjuntando memoriales de servicio y los respectivos informes de sus superiores, el Gral. José de Valles y el Virrey Manuel de Guirior. ${ }^{23}$ A raíz de ello, se le concedió el grado de Coronel de Dragones con sueldo de Teniente por gracia de S.M del 27 de julio de 1776, posteriormente en el año 1778 pidió a la Corona el sueldo correspondiente a su cargo y graduación de coronel. ${ }^{24}$ Estas gestiones promovidas por Avilés para la obtención de gracias y mercedes debían contar no solo con la acumulación de méritos y servicios por parte del agente, sino también -y sobre todo- con la validación de sus superiores, quienes debían dar confirmación de las acciones, así como de la fama y honor del agente solicitante. El memorial presentado por Avilés rescata la "consideración de su servicio", "la antigüedad de siete años de teniente coronel", "el trabajo que ha dispensado en la instrucción de las milicias" el "ir a la frontera de Chile por la causa de la guerra" así como también es indicada su "acreditada conducta y satisfacción de sus superiores" ${ }^{25}$

\section{Avilés durante las sublevaciones tupacamaristas}

Los sucesos que se desarrollaron hacia finales de 1780, luego de la captura y asesinato del corregidor de Tinta, Antonio de Arriaga, dieron curso a la rebelión generalizada en amplias regiones del virreinato del Perú y del virreinato del Río de la Plata. Estos hechos marcaron un punto de quiebre en la trayectoria de

\footnotetext{
22 AGI, LIMA, 653, N. 186 Carta N 1165 de Manuel de Amat y Junyent, Virrey de Perú, a Julián de Arriaga, secretario de Marina e Indias, [en línea] http://pares.mcu.es/ParesBusquedas20/catalogo/description/3545116?nm.

${ }^{23}$ Manuel de Guirior y Portal. Aoyz (Navarra), 1708 - Madrid, 1788. Marqués de Guirior (I), marino, sexto virrey del Nuevo Reino de Granada (1772-1776) y trigésimo segundo virrey de Perú (1776-1780). Ver: Salmoral, Manuel Lucena. "Manuel de Guirior y Portal" en Real Academia de la Historia, Diccionario Biográfico electrónico. [en línea] http://dbe.rah.es/biografias/14901/manuel-de-guirior-y-portal.

${ }^{24}$ AGI, LIMA, 655, N.3 Carta N 95 de Manuel de Guirior, Virrey de Perú, a José de Gálvez, secretario de Indias. Archivo General de Indias, LIMA, 658, N.5 Carta Nº 304 de Manuel de Guirior, Virrey de Perú, a José de Gálvez, secretario de Indias, [en línea] http://pares.mcu.es/ParesBusquedas20/catalogo/description/3595201?nm.

${ }^{25}$ AGI, LIMA,653,N.186. Carta N 1165 de Manuel de Amat y Junyent, Virrey de Perú, a Julián de Arriaga, Secretario de Marina e Indias, [en línea] http://pares.mcu.es/ParesBusquedas20/catalogo/ description/3545116?nm.
} 
Avilés, la cual hasta el momento no distaba a la de otros miembros de la oficialidad. ${ }^{26}$

En este contexto el coronel Avilés fue convocado por el virrey del Perú Agustín de Jauregui ${ }^{27}$, quien lo envió al mando de un regimiento de 200 pardos milicianos desde Lima, en auxilio de los españoles sitiados en el Cuzco, frente a las huestes de Tupac Amaru II. Luego de organizar la defensa de la plaza y repeler varios ataques con éxito, en el año 1781 se incorporó a las columnas del comandante general don José del Valle encomendándosele la dirección de la retaguardia. ${ }^{28}$

Después de la captura de Tupac Amaru II quien fuera torturado y ejecutado, los grupos que participaron en los levantamientos fueron indultados. Sin embargo, las revueltas no tardaron en propagarse nuevamente ahora bajo el mando de Diego Cristóbal Condorcanqui Castro, primo de Tupac Amaru II. Bajo estas nuevas circunstancias el 4 de septiembre de 1782 sobrevino la muerte del general Valle quien se encontraba en viaje de inspección al proceso de pacificación de las provincias de Urubamba y Calca. Debido al inesperado fallecimiento, el Inspector Gral. Avilés quedo al mando de las tropas siendo encargado de pacificar la región y capturar a Diego Cristóbal Condorcanqui Castro. $^{29}$

Finalmente, el líder indígena fue apresado el 15 de febrero junto a miembros de su familia. A todos se les formó oficio de la Real Justicia y los jueces comisionados a dictar una sentencia ejemplar, fueron el coronel de dragones Gabriel de Avilés comandante general de las Armas de Cuzco y el

\footnotetext{
${ }^{26}$ En referencia a estos sucesos pueden consultarse los trabajos de Stern (1990), O'Phelan (1995) y Serulnikov (2006).

27 Agustín de Jáuregui y de Aldecoa. Lecaroz (Navarra), 1711 - Lima (Perú), 1784. Militar, gobernador de la Capitanía General de Chile (1772-1780), virrey del Perú (1780-1784). Medina, José Toribio (1906) Diccionario biográfico colonial de Chile. Imprenta Elezeviriana, Santiago de Chile, pp. 430-431.

28 "Estado en que se apuntan los nombres y las graduaciones de los comandantes de las columnas destinadas a operar contra el rebelde José Gabriel Tupac-Amaru; las fuerzas y tropas de que se compone cada una, y las provincias por donde deben seguir su marcha, hasta el punto de reunión prevenido." En: Relación histórica de los sucesos de la rebelión de José Gabriel Tupac-Amaru, en las provincias del Perú, el año de 1780. Imprenta de Estado, Buenos Aires, 1836, [en línea] http://www.cervantesvirtual.com/obra-visor/relacion-historica-de-los-sucesos-de-larebelion-de-jose-ga briel-tupacamaru-en-las-provincias-del-peru-el-ano-de-1780-0/html/ff9844fe-82b1-11df-acc7-002185ce664.html.

${ }^{29}$ AGI, LIMA, 662, N. 45 Carta N.o 148 de Agustín de Jáuregui, Virrey de Perú, a José de Gálvez, secretario de Indias [en línea] http://pares.mcu.es/ParesBusquedas20/catalogo/description/3621996?nm.
} 
doctor Benito de la Mata Linares, oidor de la Real Audiencia de la ciudad de los Reyes. ${ }^{30}$

A raíz de su desempeño y logros obtenidos frente a la rebelión tupacamarista en agosto de 1782, Avilés pidió se le nombrase Brigadier de Dragones y se le otorgase la pensión de una encomienda. Para ello realizó una extensa relatoría de la campaña contra las huestes de Tupac Amaru II, bajo las órdenes de José del Valle, y de la "heroica" defensa que realizó de la ciudad de Cuzco ante la amenaza de las tropas del indígena rebelde. En esta relación de servicios se adjuntaron escritos del Gral. Valle y del virrey Jáuregui refrendando el pedido de Avilés y reconociendo sus proezas. ${ }^{31}$

El Gral. José Valle en cusco el 17 de agosto de 1782 dejó constancia sobre Avilés, de

“todos los méritos [...] utilísimos que acreditó cuando el insurgente Josef Gabriel Tupa Amaro intentó apoderarse de esta ciudad al frente de sesenta mil rebeldes defendiéndola con un corto numero de milicianos totalmente ignorantes en los principios de la profesión militar, que nunca habían tomado un fusil en la mano." 32

Así también el general manifestó que Avilés "llevo a cabo las acciones mas importantes, con la gloria de haber escarmentado a los enemigos todas las veces que los atacó", así como haber prestado "servicios tan distinguidos, agregados a su exactísima conducta, aplicación y sólido honor". Por lo todo lo cual pide se le otorgue el grado de Brigadier de Dragones y una pensión de una

\footnotetext{
${ }^{30} \mathrm{~A}$ Diego Cristóbal Condorcanqui Castro se lo condenó a pena de muerte, mandado ser sacado de la cárcel donde se hallaba preso, arrastrado a la cola de una bestia de albarda, llevando soga de esparto al pescuezo, atado de pies y manos y acompañado de pregonero que manifestase su delito. Sería conducido de esta forma por las calles públicas acostumbradas al lugar del suplicio, donde a vista del público, habría de ser atenazado, después colgado por el pescuezo, y ahorcado hasta que muriese naturalmente. Posteriormente su cuerpo fue descuartizado y exhibido en las localidades insurrectas. "Sentencia contra el reo Diego Cristóval Tupac-Amaru y demás cómplices, pronunciada por los señores, don Gabriel de Avilés, y el señor don Benito de la Mata Linares".

${ }^{31}$ AGI, LIMA, 661, N. 30 Carta N. 150 de Agustín de Jáuregui, Virrey de Perú, a José de Gálvez, secretario de Indias. Ejemplar triplicado [en línea] http://pares.mcu.es/ParesBusquedas20/catalogo/description/3622027?nm.

32 AGI, LIMA, 661, N. 30. Carta № 150 de Agustín de Jáuregui, Virrey de Perú, a José de Gálvez, Secretario de Indias. Ejemplar triplicado. El resaltado es nuestro [en línea] http://pares.mcu.es/ParesBusquedas20/catalogo/description/3618106?nm.
} 
de las encomiendas militares para "portarse con la decencia y esplendor correspondiente a su nacimiento y empleos". ${ }^{33}$

De igual manera, el virrey Agustín de Jáuregui informó el 16 de octubre de 1782 a José de Gálvez que Avilés desempeñó "con feliz éxito las comisiones que le han encargado sus respectivos jefes" como también sobre "la exactitud de estos servicios" y pidió se le dispensase "gracia en premio de su experimentado valor, celo, aptitud y amor a vuestro real servicio". ${ }^{34}$

La respuesta a tan alta distinción llego en el año 1784 cuando el virrey del Perú informó del arribo por despacho de la Secretaría de Indias de una Real Orden fechada en 5 de octubre de 1783, en que S.M. concedía el grado de brigadier al coronel de caballería Gabriel de Avilés. De manera que, al igual que su padre pero con 48 años, alcanzó dentro de los ejércitos del Rey el escalafón más bajo dentro del generalato. ${ }^{35}$

Finalizada la campaña contra los rebeldes y aún siendo comandante de Armas de Cuzco en 1782, Avilés con 47 años contrajo matrimonio con la marquesa Doña María Mercedes Risco y Ciudad, de 30 años, viuda de Diego Bernardo Jiménez de Morales y Arcaute, ${ }^{36}$ II marques de Santa Rosa de Lima. ${ }^{37}$ Para la época la condición de casado se asimilaba a un cierto grado de sazonada discreción. No obstante, se recelaba que el agente casado experimentase el embarazo de excesivos compromisos familiares. De manera que correspondiendo al agente la función de "páter familia" descuidara los intereses del reino en favor de los de su prosapia (Pereyra, 2017: 29). Por lo tanto, se encontraban limitados a ocupar puestos en la administración quienes poseyeran grado de parentesco con quienes realizaran los nombramientos para las plazas vacantes, el grado de conexión incluía a parientes, criados, o allegados. Esta prohibición se hallaba determinada para personas en cuarto grado de filiación con virreyes, presidentes, oidores, alcaldes del crimen, fiscales, contadores de

\footnotetext{
${ }^{33}$ AGI, LIMA, 661, N. 30. Carta № 150 de Agustín de Jáuregui, Virrey de Perú, a José de Gálvez, Secretario de Indias. Ejemplar triplicado. El resaltado es nuestro [en línea] http://pares.mcu.es/ParesBusquedas20/catalogo/description/3618106?nm.

${ }_{34}$ AGI, LIMA, 661, N. 30. Carta № 150 de Agustín de Jáuregui, Virrey de Perú, a José de Gálvez, Secretario de Indias. Ejemplar triplicado. El resaltado es nuestro [en línea] http://pares.mcu.es/ParesBusquedas20/catalogo/description/3618106?nm. El resaltado es nuestro.

${ }^{35}$ AGI, LIMA, 668, N. 40. Carta N.o 343 de Agustín de Jáuregui, virrey de Perú, a José de Gálvez, secretario de Indias [en línea] http://pares.mcu.es/ParesBusquedas20/catalogo/description/3548325?nm.

${ }^{36}$ Hijo de Don Diego Bernardo Jiménez de Morales padre, quien habían apoyado a Felipe V frente al Archiduque Carlos, resultó recompensado por el monarca borbón con el marquesado de Santa Rosa de Lima, además de ser enviado al Perú con orden de administrar varias encomiendas de indios dedicándose en este virreinato a su vez al comercio de telas europeas de lujo.

${ }^{37}$ Mendiburu, Manuel (1874) Diccionario histórico-biográfico del Perú. Tomo primero. Lima, p. 428
} 
cuentas, gobernadores, corregidores, alcaldes mayores, oficiales reales $\mathrm{u}$ otros ministros. $^{38}$

\section{Vínculos, méritos y servicios}

Perteneciente a la elite de la sociedad limeña la marquesa gozaba de una cómoda posición económica producto de los bienes de su propia familia y de los acumulados en sus primeras nupcias. De igual manera ostentaba gran reconocimiento por vivir consagrada a ejercicios religiosos y por sus ocupaciones al servicio de los pobres, buscándolos y dispensándoles los beneficios de su caridad. El "rol doméstico" de las mujeres era valorado en función de los hombres a quienes acompañaban. De manera que además de su propia fama, los agentes debían procurar la de su mujer, si la tuviera, pues esta no solo debía ser inocente, sino también libre de toda sospecha. En tanto, el gobierno del hogar, las acciones benéficas, las reuniones sociales y los ejercicios religiosos, todos ellos menesteres femeninos, se apreciaban en función de cómo contribuían a la carrera del agente a quienes acompañaban, ya fuera en calidad de esposas, madres, hermanas, etc. Doña María Mercedes Risco y Ciudad no acompañó a su esposo en ninguno de sus empleos fuera de la capital peruana, sin embargo, se mantuvo abocada a obras de caridad y devoción.

Posteriormente, ya en diciembre de 1783, Avilés pidió ser relevado del cargo de Comandante de Armas de la ciudad de Cusco debido a sus enfermedades, continuos accidentes y los achaques de su edad (48 años), lo cual le fue concedido por el virrey. Sin embargo, siguió en el cargo de Sub-Inspector General, cargo con el cual había pasado desde la Capitanía General de Chile al Virreinato del Perú. ${ }^{39}$

A raíz de la muerte de su hermano mayor José Avilés y del Fierro en el año 1784 y luego de la de su hermano Miguel en 1785, el brigadier Avilés pidió en carta de 20 de enero de 1788 se le concediera el título de Marqués de Avilés exceptuándosele del pago de media anata y lazas a perpetuidad. El pedido se formó apelando a los 60 años de servicio prestados por su padre Don José, así como por los brindados por sus "augustos hermanos mayores", sumados a los treinta y cinco años que tenía el brigadier Avilés prestados en los ejércitos,

\footnotetext{
${ }^{38}$ Recopilación de Indias. Ley 27 del tít. II del lib. III

${ }^{39}$ AGI, LIMA, 663, N. 67 Carta N. 289 de Agustín de Jáuregui, Virrey de Perú, a José de Gálvez, secretario de Indias, [en línea] http://pares.mcu.es/ParesBusquedas20/catalogo/description/3624829?nm.
} 
subrayando particularmente los méritos obtenidos por la defensa de la ciudad de Cusco. ${ }^{40}$

Es importante tener presente que entre los elementos que constituían incapacidades para el ejercicio de cargos en la administración y mantener los alcanzados, se encontraba el de no ser hombres libres o el ser deudores de la Real Hacienda. Recordemos que para algunos cargos de la administración se hallaba reglamentado el pago de la "media anata". Esta contribución consistía en el desembolso de media anualidad de la retribución que todo agente designado para un cargo debía hacer al erario. Estaban también obligados a efectuarla los súbditos que hubieran recibido algún tipo de merced real, tales como compensaciones por honores, dignidades, sucesión de títulos nobiliarios, etc. ${ }^{41} \mathrm{El}$ "derecho o pago de lanzas" por otra parte, se encontraba establecido para los nobles, quienes se hallaban obligados a servir en la defensa del reino, y constituía otro de los desembolsos que estaban obligados a realizar quienes además de poseer un título de nobleza detentaban el ejercicio de algún cargo dentro de la administración. Las deudas ante la Real Hacienda muchas veces fueron derogadas por merced real o aplazadas, asimismo frente a las constantes crisis financieras de la monarquía los deudores muchas veces podían, si contaban con los medios, cancelar sus moras con ciertos beneficios, frente a la urgencia de la Corona en solucionar sus problemas económicos.

Algunos autores confirman la concesión de la gracia real solicitada por Gabriel de Avilés, sin embargo, no dan referencia precisa sobre las fuentes utilizadas o mencionan citas poco claras. ${ }^{42}$ Por otro lado, sabemos que por medio de su hermano Don Ramon como apoderado, Gabriel de Avilés, consignó como finca para asegurar el pago de lanzas y medias anatas correspondientes al título de Marqués de Avilés cinco acciones del Banco Nacional de San Carlos, ya que no poseía más que su sueldo y las acciones de dicho Banco. Estas gestiones se encuentran fechadas en 5 de febrero de 1791 en el protocolo 20502, folio 218 (Mantilla Tascón, 1987: 60) y evidencian la red de vínculos que se pusieron en acción en el desarrollo de estas gestiones. A partir del año 1792 el brigadier Avilés comenzó a firmar sus escritos como Marqués de

\footnotetext{
${ }^{40}$ AGI, LIMA, 679, N. 31 Carta N. 104 de Teodoro de Croix, virrey de Perú, a Antonio Valdés, secretario de Marina, Guerra, Hacienda, Comercio y Navegación de Indias [en línea] http://pares.mcu.es/ParesBusquedas20/catalogo/description/3665201?nm.

${ }_{41}$ "Durante toda la existencia del Virreinato del Rio de la Plata, la doctrina siguió insistiendo en la media anata, que solo ligaba a quienes obtenían del Rey empleos, dignidades, gracias o mercedes. En el terreno de los hechos, su aplicación práctica fue siempre resistida, a menudo bajo la forma de consultas inocentes. Nunca ocupo, en consecuencia, un lugar importante dentro de los cincuenta impuestos que percibía la Contaduría de Buenos Aires" (Leiva, 1987: 280).

${ }^{42}$ El autor más referenciado es: Palma (2007).
} 
Avilés, y sus órdenes e instrucciones comenzaron a ser remitidas también bajo el mismo título. ${ }^{43}$

Todas estas comisiones representan el elevado interés de Avilés en resguardar para sí el título nobiliario con el cual fuera premiado su padre. En primera instancia apelando a la monarquía para ser dispensado de los correspondientes pagos, y posteriormente fracasada esta acción, enfrentando los costos de su traspaso, más aún sabiéndose carente de descendencia que perpetuase la sucesión de sus honores.

Aún con su cargo de Sub Inspector de tropas Gabriel de Avilés, Comandante General de las Armas del Cuzco, el 20 de enero de 1787 solicitó su regreso a España, lo cual le fue negado. ${ }^{44}$ La negativa de los agentes a ocupar cargos o a efectuar traslados de jurisdicciones hacia regiones menos favorables constituían una grave falta hacia la obediencia y sumisión real que tales agentes debían manifestar, llegando a ser un obstáculo para el desarrollo de una carrera en la administración. En este sentido se establecía que "se le transfiera [al agente] aunque lo rehúse, a los virreinatos y gobiernos de las Indias, pues ninguno que sirva al Estado puede substraerse a las cargas de él ni frustrar el derecho que tiene el mismo Estado de valerse de sus talentos y virtudes" (Urquijo, 1998: 197). Acatar una negativa de pedido de traslado también puede considerarse como un gesto de obediencia y sumisión.

El 20 de febrero de 1788 Avilés realizó otro pedido a Madrid. Esta vez solicitó se le nombrase Inspector General de Tropas del Perú, ya que solo ostentaba el de Sub-inspector sin conocer los motivos de tal decisión. Para formar este pedido argumentó que sus antecesores en el cargo poseían el título de inspectores, y él por poseer el de Sub-Inspector encontraba en algún modo debilitada la autoridad necesaria para el desempeño de su ministerio, ya que se confundía su empleo superior con el de Sub-Inspector de pardos y morenos. De la misma manera el Brigadier solicitó el título de Lugarteniente General que ostentaron sus antecesores en el cargo. Ambos pedidos fueron presentados por Avilés y enviados a Madrid por el virrey del Perú Teodoro de Croix junto a la correspondiente nota virreinal.

En dicha nota virreinal, al contrario de lo que estipulaba la costumbre, el virrey no realizó ninguna defensa de la solicitud del Sub-Inspector Avilés. De

\footnotetext{
${ }^{43}$ AGI, LIMA, 704, N. 97 Carta N.. 279 del virrey Francisco Gil de Taboada y Lemos al Conde del Campo de Alange, secretario de Estado de la Guerra [en línea] http://pares.mcu.es/ParesBusquedas20/catalogo/description/3897494?nm.

${ }^{44}$ AGI, LIMA, 676, N. 6. Carta N. 540 de Teodoro de Croix, virrey de Perú, a José de Gálvez, secretario de Indias, Marqués de Sonora [en línea] http://pares.mcu.es/ParesBusquedas20/catalogo/description/3657112?nm // AGI, LIMA, 652, N. 77. Carta N.o 408 de Manuel de Amat y Junyent, virrey de Perú, a Julián de Arriaga, secretario de Indias [en línea] http://pares.mcu.es/ParesBusquedas20/catalogo/description/359115?nm.
} 
Croix manifestó desconocer la situación de los antecesores en el cargo, aspecto sobre lo cual se fundamentaba el pedido. Finalmente, por la Real Orden de 18 de mayo de 1789 el pedido realizado por Avilés fue rechazado. Durante todo el gobierno del virrey Teodoro de Croix (1784-1790) Avilés no recibió respuestas favorables a ninguna de sus demandas, así como tampoco gracias reales o licencias. ${ }^{45}$

Sin embargo, la suerte de Avilés cambiaría con la llegada al Perú del nuevo virrey Francisco Gil de Taboada (1790-1794), este a diferencia de su antecesor Teodoro de Croix viabilizaría varias de las peticiones de Avilés. Esto le permitirá conseguir el grado de Mariscal de Campo por Real Orden de 22 de abril de 1791. De igual manera, en cumplimiento de la Real Orden de 29 de abril de 1792, se dispuso que se le considerase el sueldo anual de 9.000 pesos y se le abonase la diferencia desde la fecha del Real Decreto de 23 de febrero de 1788 de su concesión. ${ }^{46} \mathrm{Su}$ carrera de asensos dentro del ejercito no se detendría, cuatro años después de haber sido nombrado Mariscal de Campo, Avilés informó al Conde de Campo Alegre ${ }^{47}$ en 23 de junio de 1796 haber recibido asenso al grado de Teniente General de los Ejércitos el 2 de noviembre de 1795, siendo el escalafón de mayor jerarquía que alcanzaría Avilés en toda su carrera militar. ${ }^{48}$

\footnotetext{
${ }^{45}$ AGI, LIMA, 679, N. 32 Carta N.o 105 de Teodoro de Croix, virrey de Perú, a Antonio Valdés, secretario de Marina, Guerra, Hacienda, Comercio y Navegación de Indias [en línea] http://pares.mcu.es/Pares Busquedas20/catalogo/description/3665204?nm. Contreras, Remedios y Carmen Cortés. (1972) "Catálogo de la colección Mata Linares IV". En Archivo Documental Español, Tomo XXIX. Edit. Real Academia de la Historia. Madrid, p. 206; AGI, LIMA, 686, N. 117 Carta N.. 565 de Teodoro de Croix, virrey de Perú, a Antonio Valdés, Secretario de Hacienda, Marina y Guerra de Indias, [en línea] http://pares.mcu.es/ParesBusquedas20/ catalogo/description/3702549?nm.

46 Sobre el nombramiento como Mariscal de Campo: AGI, LIMA, 698, N. 49 Carta N.o 125 del virrey Francisco Gil de Taboada y Lemos, a Manuel de Negrete y de la Torre, Conde del Campo de Alange, secretario de la Guerra [en línea] http://pares.mcu.es/ParesBusquedas20/catalogo/ description/4451820?nm. Sobre la corrección respecto a su salario como Sub-Inspector General: AGI, LIMA, 704, N. 97 Carta N.o 279 del virrey Francisco Gil de Taboada y Lemos al Conde del Campo de Alange, secretario de Estado de la Guerra [en línea] http://pares.mcu.es/ParesBusquedas20/catalogo/ description/3897494?nm.

${ }^{47}$ Manuel de Negrete y de la Torre, II Conde de Campo Alegre. Político, militar, diplomático y aristócrata español. Madrid (España) 1736 - París (Francia) 1818. 1790 - 1795 Secretario de Estado y del Despacho Universal de la Guerra de España e Indias, 1795-1801 embajador español en Viena, 1802 - 1808 embajador español en Lisboa, 1808 - 1811 Secretario de estado, Ministro de negocios extranjeros, 1811- 1814 embajador español en París. Ver: Rodríguez-Ponga y Salamanca, Pedro. "Negrete y de la Torre, Manuel" en Real Academia de la Historia, Diccionario Biográfico electrónico. [en línea], http://dbe.rah.es/biografias/13546/manuel-de-negrete-y-de-latorre.

48 AGI, LIMA, 733, N. 66 Carta sin número del Marqués de Avilés al Conde de Campo de Alange, [en línea] http://pares.mcu.es/ParesBusquedas20/catalogo/description/4218343?nm.
} 


\section{Cuadro I}

Grados obtenidos por Gabriel de Avilés dentro del escalafón militar

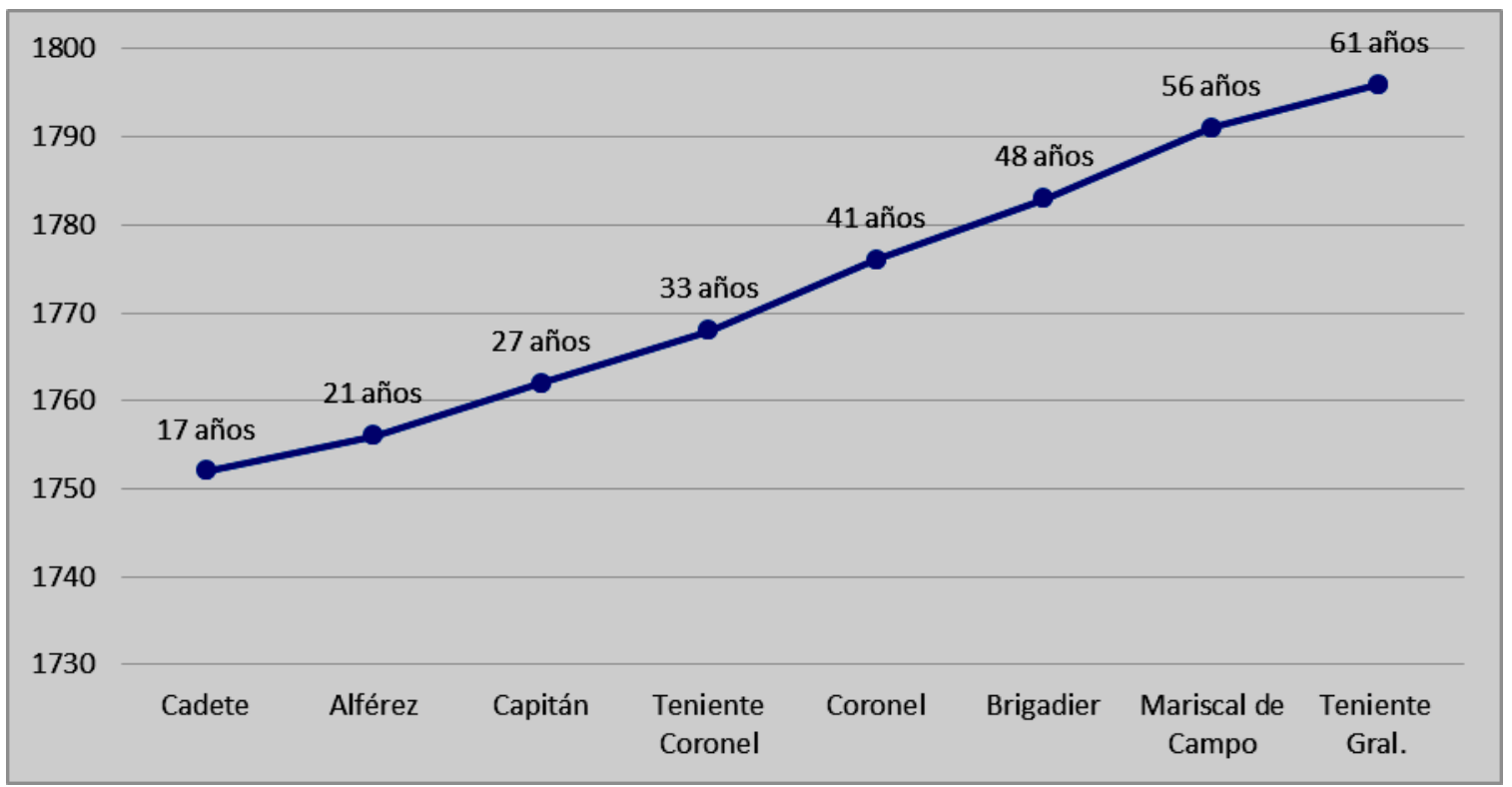

Los cambios de autoridades y la valoración del Marqués en referencia a su "aptitud, méritos y servicios", consiguieron se lo nombrase Capitán General y Presidente de Chile y de su Real Audiencia, reemplazando en el cargo a Ambrosio O'Higgins quien pasaría a ser el nuevo virrey del Perú. El nombramiento de Avilés, recibido en febrero de 1796, le consignaba además un sueldo de 10.000 pesos anuales, el pago de media anata por no ser sueldo puramente militar. ${ }^{49}$ Conjuntamente con la designación de Ambrosio O'Higgins como virrey del Perú, por despacho reservado se estableció, como era costumbre, los nombres de quienes en caso de fallecimiento del virrey se ocuparían del gobierno de los "dominios del Rey, asegurando la conservación y los beneficios de los vasallos, manteniéndolos en paz y justicia". Apelando a características como "celo, experiencia y grado" se estableció el primer lugar para el Marqués de Avilés, el segundo para Francisco de la Mata Linares y el tercero para Joaquín del Pino. ${ }^{50}$

A lo largo de toda la reconstrucción que hemos desarrollado hasta aquí, es relevante destacar el peso que ha tenido la construcción de redes de vínculos personales durante la trayectoria de Avilés, además de su capital de servicio en los ramos militares y de gobierno. En tal sentido, la articulación de estas redes se evidencia en las gestiones realizadas en Madrid por su hermano Ramon, así

${ }^{49}$ AGS, SGU, LEG, 7129, 17, Virreinatos de Perú y Nueva Granada y Gobierno de Chile, [en línea] http://pares.mcu.es/ParesBusquedas20/catalogo/description/1302511?nm.

50 AGS, SGU, LEG, 7325, 4, Virreinato del Perú. Interinos [en línea] http://pares.mcu.es/ParesBusquedas20/catalogo/description/1311433?nm. 
como en su inserción social dentro de la elite cuzqueña a través de su matrimonio con la Marquesa María Mercedes Risco. De igual manera pueden advertirse en la importancia que representan para su "carrera" los vínculos formados con sus superiores como el Gral. José Valle, así como también con los virreyes Agustín de Jauregui y Francisco Gil de Taboada durante sus respectivos gobiernos. Su relación con el virrey Teodoro de Croix refleja que contar con el respaldo del virrey podía constituir la llave para alcanzar ciertos objetivos o representar en una verdadera traba.

\section{De Capitán General de Chile a Virrey del Río de la Plata}

Luego de un viaje "temible", según sus propias palabras, debido a la condición de los mares en invierno, la fragata mercante en la que se trasladó arribó a Valparaíso. En este lugar el flamante gobernador comenzó sus primeras acciones de gobierno, deteniéndose lo conveniente para reconocer $\mathrm{e}$ inspeccionar las fortificaciones del lugar e impartir disposiciones al respecto. Consumada esta parada siguió camino durante dos días, hacia la capital donde se realizaron las ceremonias públicas de su recibimiento, el día 19 de septiembre. ${ }^{51}$ El cabildo de Santiago de Chile acordó que se sacaran del ramo de Balanza 1.500 pesos para que la ciudad recibiera con el "esplendor y decencia debida" al Presidente, Gobernador y Capitán General Gabriel Avilés. ${ }^{52}$

La obra de gobierno de Avilés obedeció a las mismas políticas que la monarquía intentaba desarrollar en todos sus territorios americanos. En el caso de la Capitanía General de Chile principalmente refirieron, en el plano interno, a la conservación de la paz con los "indios infieles" y el fomento de la población de Osorno. Estos importantes asuntos pendientes resultaban tareas dificultosas según palabras del gobernador "debido a que los indios deciden en sus congresos mediados por su embriagues". ${ }^{53}$

El clima internacional y la amenaza de potencias extrajeras sobre el territorio signó las acciones de gobierno de Avilés hacia la fortificación de algunos enclaves costeros, ante la hipótesis de un ataque en plazas como Coquimbo-La Serena (al norte) Valparaíso (al centro, acceso directo a la capital) y Valdivia (al sur). Consecuentemente la hipótesis de conflicto fue confirmada

51 AGS, SGU, LEG, 7325, 4, Virreinato del Perú. Interinos [en línea] http://pares.mcu.es/ParesBusquedas20/catalogo/description/1311433?nm.

${ }^{52}$ Actas de sesiones del Cabildo de Santiago de Chiles. Sesión de 12 de abril de 1796, [en línea] http://www.historia.uchile.cl/CDA/fh article/0,1389,SCID\%253D15900\%2526ISID\%253D573\%25 26JNID\%253D27,00.html Concurrieron en diputación al recibimiento de Avilés en el puerto de Valparaíso el alcalde de Segundo Voto, don Pedro de Ugarte, acompañado del señor Regidor Doctor don Francisco Javier de Larraín .

${ }^{53}$ AGS, SGU, LEG, 7129, 17, Virreinatos de Perú y Nueva Granada y Gobierno de Chile [en línea] http://pares.mcu.es/ParesBusquedas20/catalogo/description/1302511?nm. 
por la Real Orden muy reservada de 23 de junio de 1796, por la cual se lo anotició del estado de hostilidades iniciado con Inglaterra, respondiendo el gobernador en 12 de diciembre de 1796 sobre los reparos que tomaría al respecto en la defensa del país. ${ }^{54}$ En sintonía con su preocupación defensiva fundó una fábrica de pólvora en las afueras de Santiago, sobre la ladera norte del cerro San Cristóbal, con el fin de proveer a las tropas y a la industria minera.

No obstante, su obra de gobierno no solo respondió a la necesidad defensiva de la monarquía, sino también debió atender a cuestiones que fomentasen el adelantamiento del reino y al desarrollo de empresas que propiciasen la felicidad de los súbditos del rey. En este sentido obras de gran relevancia a su cargo fueron la construcción de tajamares sobre el río Mapocho, la continuación del proyecto de su antecesor de pavimentación de las calles de la capital virreinal, la reparación del hospital San Juan de Dios, la asistencia a la Casa de Mujeres Recogidas y Casa de Niños Expósitos, en procura asegurarles rentas mediante la creación de una lotería semanal y al auspicio de algunos vecinos acaudalados. De igual manera, en cooperación con Manuel de Salas (alcalde del cabildo de Santiago) se emprendieron acciones que buscaron el fomento al cultivo del lino, la entrega de tornos para el desarrollo de la industria de hilado y el apoyo para la creación de la Academia de San Luis en 1797 (Barros Arana, 1886).

Para el año 1799, luego de cuarenta y siete años al servicio de la Corona, treinta y uno de ellos en tierras americanas en distintos puestos de la administración y el ejército, fue nombrado virrey del Río de la Plata, uno de los más altos cargos que un agente podía alcanzar dentro de la administración indiana. ${ }^{55}$ Avilés llegó al cargo virreinal, al igual que sus seis antecesores en el puesto, con una vasta carrera militar y sobre todo con una gran experiencia en cargos de administración y gobierno dentro de la monarquía. Hasta el año 1801 Avilés estuvo al frente del virreinato del Río de la Plata, cuando fue promovido al cargo de virrey del Perú.

\section{Conclusiones}

El extenso recorrido de Avilés dentro de la administración real lo coloca como arquetipo del agente real de finales del siglo XVIII. Siendo el virrey natural de

\footnotetext{
54 AGI, ESTADO, 85, N. 41. Presidente de Chile acusa recibo Real Orden [en línea] http://pares.mcu.es/ParesBusquedas20/catalogo/description/67682?nm.

55 En la cima de la "jerarquía" de gobierno para agentes reales asentados en América se encontraban los cargos virreinales de las cuatro jurisdicciones y las presidencias de las Reales Audiencias, aunque todos ellos con distintas prerrogativas, jurisdicciones y privilegios.
} 
los nuevos sectores sociales beneficiados por el cambio dinástico y por los servicios prestados a la Corona por sus familiares.

Como logramos reconstruir, la trayectoria de Avilés estuvo atravesada por venalidades, así como también por los servicios y méritos brindados y conseguidos en los ejércitos reales, que le valieron una carrera con constantes ascensos. Principalmente gracias a su participación durante su juventud en la península en la Guerra de los Siete Años, así como a los éxitos conseguidos durante su adultez en América con la represión de los levantamientos indígenas en la Araucanía y sobre todo por los méritos alcanzados gracias a sus acciones frente a las sublevaciones tupamaristas, tanto en la defensa del Cusco como en el sometimiento de los rebeldes. Todos estos logros le posibilitaron poder escalar en la jerarquía militar desde el grado de cadete hasta alcanzar el de Teniente General dentro del generalato.

Sin embargo, sus servicios a la Monarquía no solo se restringieron al plano militar ya que ocupó cargos de gobierno y administración, como la Gobernación del Callao, la Capitanía General de Chile, el Virreinato del Río de la Plata y finalmente el Virreinato del Perú. Lo cual evidencia un proceso escalonado en la toma de oficios dentro de la monarquía hasta alcanzar el cenit de su carrera con la obtención del asiento virreinal.

A lo largo de toda la carrera de Avilés dentro de la administración real, podemos evidenciar el clima de época que atravesaba la monarquía, producto de un contexto de conflictos entre monarquías y dificultades económicas. En este sentido, y solo por nombrar algunos ejemplos, podemos rescatar su tarea en la defensa de la costa del Pacífico como instructor de caballería, así como sus oficios de Gobernador del Callao y posteriormente Capitán del Reino de Chile. De igual manera la búsqueda de recuperar las arcas del reino se evidencia en su obra de gobierno en el Perú, Chile y en el Río de la Plata, a través del fomento a determinados ramos, así como también los intentos de saneamiento de las cuentas locales.

La trayectoria de Avilés dentro de la administración real a su vez no escapó de las estructuras propias de la monarquía. En este sentido ante cada pedido efectuado a la Corona, tanto para la concesión de gracias como para el acceso a ascensos, Avilés tuvo que realizar sendas relatorías y presentar nutridas hojas de servicios sobre sus acciones. De la misma manera todos estos documentos debieron contar con el favor de sus superiores, quienes gestionaban sus pedidos, garantizaban sus méritos y realizaban semblanzas sobre su persona. En este punto, cabe resaltar que la construcción de vínculos con sus pares y superiores resultaba un capital inestimable. Tal como consideramos evidencia el caso del vínculo entre Avilés y el Virrey de Croix, no bastaba con solo demostrar un buen desempeño en los cargos, también debía 
lograrse el visto bueno de los superiores, de manera que estos acompañaran las solicitudes de ascensos y otorgamiento de gracias.

La carrera del virrey debió contar además con recursos económicos para solventar el pago de medias anatas de los oficios alcanzados, como también el pago de lanzas para la obtención del título de IV Marques de Avilés. Estas preocupaciones se evidencian en las solicitudes interpuestas para la reparación de sueldos, así como los pedidos ante las autoridades para ser licenciado de sus obligaciones pecuniarias. Cada uno de estos pedidos, aunque contaron con respuestas adversas a los intereses de Avilés, se fundaron sobre elementos que el agente consideraba suficientes para conseguir la gracia real.

Por sobre todo, nos interesa destacar cómo en cada uno de los momentos que hemos reconstruido de la carrera de Avilés se puso en juego de manera variable el ideal de "buen gobierno", gracias al accionar de los distintos agentes asentados tanto en la Corte como en América. Fue a través de la interpretación de este ideal que se justificaban y caracterizaban las acciones, logros, méritos y servicios de Avilés para la obtención de prerrogativas o privilegios por parte de la Monarquía, tal como pudimos apreciar en sus solicitudes y en las recomendaciones de sus superiores. Hemos podido recuperar alusiones referentes a Avilés tales como, hombre de "honor y graduación", de "celo, experiencia y grado", con "aptitud, mérito y servicio", poseedor de "esplendor y decencia", y dedicado a la "paz y justicia", entre otras. Alusiones todas que presentaban una relación directa con varios elementos que fueron ponderados por la Monarquía tanto para el ingreso como para la permanencia y ascenso de los hombres en los cargos de la administración, tanto en la península como en las Indias. Pero por sobre todo evidenciaban que el desempeño del sujeto en cuestión -en nuestro caso, Avilés- se alineaba de manera eficaz con los objetivos que la Monarquía perseguía en sus dominios: asegurar la defensa militar, pacificar las fronteras con los indígenas, sanear las finanzas locales, promover actividades económicas (entre otras). Aquellas características demuestran la identificación del agente con la mayor "ejecutividad" pretendida por la corona ("celo", "servicio", "merito", "honor", "aptitud", "decencia") y con la eficacia en la concreción de objetivos caros a las necesidades de la monarquía (fiscales, territorial, militares) sin que su consecución implicara el quiebre con las comunidades locales.

El caso de Avilés nos permite vislumbrar, dentro del proceso de militarización de los cuerpos políticos, que la faz militar fue un elemento central para el arribo de funcionarios a los cargos de gobierno, pero no el único y, quizás, ni siquiera el más importante. Como vimos, los elementos que cimentaron su carrera como agente borbónico respondieron a criterios flexibles y permeables vinculados al "buen gobierno", propios de un momento histórico preciso de la Monarquía Hispánica. En tal sentido, debemos tener presente que 
tanto mérito y servicio, decencia, fama, honor, grado de nobleza, filiaciones, experiencia, respeto, género, estado, nivel económico, obediencia y sumisión real, edad, validación de sus superiores, ser hombre libre, no ser deudor, control real, etc. eran criterios flexibles. Consideramos que comprender los juicios que se cernían sobre la selección y evaluación de los agentes reales nos permite identificar de qué manera ese ideal de "buen gobierno" era dotado de sentido por los distintos integrantes (e intereses) de la monarquía.

\section{Referencias bibliográficas}

Amadori, A. (2016). Los territorios americanos y su integración en el mundo hispánico: itinerarios historiográficos entre el paradigma colonial y la monarquía policéntrica. Programa Interuniversitario de Historia Política, (78), febrero, [en línea] http://historiapolitica.com/dossiers/los-territoriosamericanos-y-su-integracion-en-el-mundo-hispanico-itinerarioshistoriograficos-entre-el-para digma-colonial-y-la-monarquia-policentrica

Abásolo, E. (2005). Estilo militar de gobierno y disciplinamiento de la administración virreinal rioplatense bajo los borbones. Revista de historia del derecho, (33), 13-67.

Andújar Castillo, F. (2004). El sonido del dinero/ Monarquía, ejercito y venalidades en la España del siglo XVIII. Edit. Marcial Pons.

Andújar Castillo, F. (2006). Servicios para la guerra, mercedes para las oligarquías. Las recompensas de la Guerra de Sucesión en Andalucía. En Bernardo Ares, J. La sucesión de la monarquía hispánica, 1665-1725, (pp. 43-74). Vol. 1, Universidad de Córdoba, Servicio de Publicaciones: Cajastur.

Barros Arana, D. (1886). Gobierno interino del regente Rezabal I Ugarte: gobierno del Marqués de Avilés (1796-1798). En: Historia general de Chile, Vol. VII, Cap. XXI (pp. 197-222).

Benavent, R. (2002). Las oportunidades de enriquecimiento ilícito generadas por el ejercicio de la intendencia más tentadora de España: La pesquisa realizada al Marqués Avilés como Intendente de Valencia en 1762. Estudis: Revista de historia moderna, (28), 263-285.

Birocco, C. (2015). El Presidio de Buenos Aires entre los Habsburgo y los Borbones: el ejército regular en la frontera sur del imperio español (1690-1726). En: E. Reitano, y P. Possamai (Coords.), Hombres, poder y conflicto. Estudios sobre la frontera colonial sudamericana y su crisis, (pp. 117- 150). Universidad Nacional de La Plata. 
Brading, D. (1984). Bourbon Spain and Its American Empire. The Cambridge History of Latin America. Vol. 1, Colonial Latin America, (389-439), editado por Leslie Bethell. Cambridge University Press.

Cardim, P. (2005) Administração e governo: uma reflexão sobre o vocabulário do Antigo Regime. En: Bicalho, M. y Amaral Ferlini, V. Modos de gobernar: idéias e práticas políticas no imperio portugués. Séculos XVI-XIX. Ed. Alameda.

Ciaramitaro, F. (2008). Virrey, gobierno virreinal y absolutismo el caso de la Nueva España y del reino de Sicilia. Srud. his. H. mod., (30), 235-271.

Contreras, R. y Cortés, C. (1972). Catálogo de la colección Mata Linares IV. En Archivo Documental Español, Tomo XXIX. Edit. Real Academia de la Historia.

De Cadenas y López, A. (1991). Suplemento al elenco de grandezas y títulos nobiliarios españoles. Apéndice II. Títulos vacantes y títulos extranjeros cuyo uso fue autorizado en España. Instituto Salazar y Castro. Edit. Hidalguía.

Dedieu, J. P. (2000). La Nueva Planta en su contexto. Las reformas del aparato del Estado en el reinado de Felipe V. Manuscrits, (18), 113-139.

Dedieu, J.P. (2007). Lo militar y la monarquía en España. Con especial referencia al siglo XVIII. En Jiménez Estrella, A.; Andújar Castillo, F. (Eds.) Los nervios de la guerra. Estudios sociales sobre el ejército de la monarquía hispánica (s. XVI-XVIII): nuevas perspectivas, (231-250). Comares.

Fernández Albaladejo, P. (1984). Monarquía, Cortes y Cuestión Constitucional en Castilla durante la Edad Moderna. Revista de las Cortes Generales, (1), 11-34.

Forconi, M. (2019). Perfiles militares de la Tenencia de Gobernación santafesina en la era borbónica. Anuario de Estudios Americanos, (76), 1, enero-junio, 237-267, [en línea] https://doi.org/10.3989/aeamer.2019.1.10.

Guerra, F.X. (2012). Hacia una nueva historia política: actores sociales y actores políticos. En Lempérière, A. y Lomné, G. (Comps.) Figuras de la modernidad Hispanoamérica. Siglos XIX-XX, (pp. 19-39). Universidad Externado de Colombia, Taurus, IFEA.

Guerra, F.X. (2003). De la política antigua a la política moderna: algunas proposiciones. Anuarios IHES, Vol. 18, 201-201.

Halperin Donghi, T. (1961). Tradición política española e ideología revolucionaria de Mayo. Eudeba.

Hespanha, A. (1984). Para uma teoria da história institucional do Antigo Regime. Poder e instituiçoes na Europa do Antigo Regime, (pp. 7-89). Colectânea de textos. 
Imízcoz Beunza, J. M. (2011). Élites administrativas, redes cortesanas y captación de recursos en la construcción social del estado moderno. Trocadero, 1 (19), 11-30.

Leiva, A. (1987). La aplicación de la media anata en el Virreinato del Río de la Plata. Revista Chilena de Historia del Derecho, (13), 269-283.

Lemperiere, A. (2008). República y publicidad a finales del Antiguo Régimen (Nueva España). Los espacios públicos en Iberoamérica: Ambigüedades y problemas. Siglos XVIII-XIX. Centro de estudios mexicanos y centroamericanos. doi:10.4000/books.cemca.1456

Lynch, J. (1973). The Spanish American Revolutions, 1808-1826. Weidenfeld and Nicholson.

Malagón Pinzón, M. (2005). La carrera administrativa en la administración pública indiana. Estudios Socio-Jurídicos, 7 (1), 279-301, enero-junio.

Mantilla Tascón, A. (1987). Catálogo de documentos notariales de nobles. Edit. Hidalguía.

Marchena Fernández, J. (1983). Oficiales y soldados en el ejército de América. Escuela de Estudios Hiapano-Americanos.

Mariluz Urquijo, J. (1998). El agente de la administración pública en las Indias. Instituto internacional de historia del derecho indiano e Instituto de investigaciones de historia del derecho.

Morelli, F. (2008). La redefinición de las relaciones imperiales: en torno a la relación reformas dieciochescas/independencia en América, Nuevo Mundo Mundos Nuevos. (8). [en línea]

\section{http://journals.openedition.org/nuevomundo/32942;DOI:10.4000/nuevo} mundo.3294.

Morelli, F. (2015). Entre el antiguo y el nuevo régimen: el triunfo de los cuerpos intermedios. El caso de la Audiencia de Quito, 1765-1830. Historia y política, (10).

O’Phelan, S. (1995). La gran rebelión en los Andes. De Túpac Amaru a Túpac Catari. Centro de Estudios Regionales Andinos Bartolomé de las Casas.

Palma, R. (2007). Tradiciones peruanas. Tercera serie. Biblioteca Virtual Miguel de Cervantes.

Pereyra, O. (2017). El poder jurisdiccional: elementos para su comprensión. En: Carzolio, M.; Pereyra, O.; Bubello, J. (Coords.) El Antiguo Régimen: Sociedad, política, religión y cultura en la Edad Moderna. EDULP. [en línea] http://www.memoria.fahce.unlp.edu.ar/libros/pm.512/pm.512.pdf.

Pérez Herrero, P. (1991). Los Beneficiarios Del Reformismo Borbónico. Metrópoli versus elites novohispanicas. HMex, XLI, 2. 
Pietschmann, H. (1996). Las reformas borbónicas y el sistema de intendencias en Nueva España: un estudio político administrativo. Fondo de Cultura Económica.

Pietschmann, H. (2003). Los principios rectores de la organización estatal en las Indias. En A. Annino, F-X. Guerra, Inventando la nación, (pp. 47-84). Iberoamérica siglo XIX.

Ravetllat Ballesté, I. (2015). ¿Por qué dieciocho años? La mayoría de edad civil en el ordenamiento jurídico civil español. Anales de la Cátedra Francisco Suárez, (49), 129-154.

Rivero Rodríguez, M. (2013). La reconstrucción de la Monarquía Hispánica: La nueva relación con los reinos (1648-1680). Revista Escuela de Historia, vol. 12 (1) [en línea] http://www.scielo.org.ar/scielo.php?script=sci arttext\&pid=S1669$\underline{90412013000100002}$

Romero, C. (1901). Memoria del virrey del Perú Marqués de Avilés. Imprenta del Estado.

Ruiz Ibáñez, J. (2016). Una historia más allá del paradigma centro-periferia. [Texto inédito, en línea:]

http://historiapolitica.com/datos/biblioteca/monarquia ruiziba\%C3\%B 1ez2.pdf

Sánchez de Tagle, E. (2010). Las reformas del siglo XVIII al gobierno; la ciudad, su hacienda, su política, su ejército. En: García Ayluardo, C. (Coord.) Las reformas borbónicas, 1750-1808. Fundación Cultural de la Ciudad de México.

Sánchez Santiró, E. (2016). Las reformas borbónicas como categoría de análisis en la historiografía institucional, económica y fiscal sobre Nueva España: orígenes, implantación y expansión. Historia Caribe, vol. XI (29) Julio-diciembre, 19-51.

Serulnikov, S. (2006). Conflictos sociales e insurrección en el mundo colonial andino. El norte de Potosí en el siglo XVIII. FCE.

Stern, S. (1990) (Comp.) Resistencia, rebelión y conciencia campesina en los Andes. Siglos XVIII al XX, I.E.P.

Tarragó, G. (2012). Espacio, recursos y territorio: la Gobernación del Río de la Plata durante el reinado de Felipe V. En: Manzín, Ó. y Ruiz Ibáñez, J. Las Indias Occidentales. Procesos de incorporación territorial a las Monarquías Ibéricas, (pp. 281327), El Colegio de México/Red Columnaria.

Tarragó, G. (2017). La articulación de los territorios de la monarquía durante el primer reformismo borbónico: gobernadores, comerciantes y compañías privilegiadas de comercio. Río de la Pata (1700-1746). Magallánica, Revista de Historia Moderna, 4 / 7 (Dossier) Julio-Diciembre. 
Trujillo, O. J. (2017). Los Habsburgo en el Río de la Plata: gobernadores de capa y espada en el Buenos Aires colonial temprano. Anuario del Instituto de Historia Argentina, 17 (2) e047. http://www.memoria.fahce.unlp.edu.ar/artrevistas/pr $.8319 /$ pr.8319.pdf

Zavala Cepeda, J. (2015). Parlamento de Negrete 1771. Los parlamentos HispanoMapuches, 1593-1803: Textos fundamentales. Edit. Universidad Católica de Temuco. 